\title{
Correction of Class II Malocclusion in a Patient Using the FORSUS Fatigue Resistant Appliance - A Case Report
}

\author{
Taher Manasawala, Vikram Shetty, Sailesh Shenava, Sushmita Batni
}

Department of Orthodontics and Dentofacial Orthopaedics, Y.M.T. Dental College and Hospital, Navi Mumbai,

Maharashtra, India

\begin{abstract}
Functional appliances, fixed or removable, are primarily orthopedic tools used to influence the facial skeleton in a growing child. Class II malocclusion with a retrognathic mandible in a non -compliant post-pubertal patient can be treated using the fixed functional appliances. One such appliance which is in common use in clinical practice today is the FORSUS Fatigue Resistant Device (FFRD). To treat a 13-year-old female patient having a class II base, a retrognathic mandible, horizontal growth pattern, convex profile, an overjet of $7 \mathrm{~mm}$, mild proclination of maxillary and mandibular incisors, Class II molar and canine relationship bilaterally, and a positive visualized treatment objective. Orthodontic department of a Dental college. FFRD. When used in the right case, the FFRD appliance can be comfortable and economical to both the patient and the clinician.
\end{abstract}

Key words: FORSUS appliance, class II malocclusion, post-pubertal, fixed functional

\section{INTRODUCTION}

Clinicians are periodically encountered with malocclusions that do not respond favorably to tooth-moving mechanotherapies because disharmony exists in the basal jaw bone. ${ }^{[1]}$ Patients with Class II Division 1 malocclusion can exhibit maxillary protrusion, mandibular retrusion, or both, together with abnormal dental relationship problems and facial esthetic disorders. These malocclusions are treated with various orthodontic and orthopedic appliances. Removable (activator, Balters bionator, Frankel) and fixed (Herbst, Jasper jumper, mandibular anterior repositioning appliance) functional appliances are commonly used to treat Class II Division 1 malocclusions during the pubertal growth period in children. ${ }^{[2]}$

\begin{tabular}{|c|l|}
\hline \multicolumn{2}{|c|}{ Access this article online } \\
\hline \multicolumn{1}{|c|}{ Publisher } & Website: \\
www.ijdms.in \\
\hline
\end{tabular}

Functional appliances are primarily orthopedic tools used to influence the facial skeleton in a growing child. ${ }^{[3]}$ The aim of functional appliance therapy is to eliminate or minimize skeletal, dentoalveolar, and muscular problems prior to the cessation of growth. Timing of treatment is critical and functional therapy or growth modification must be complete before the growth spurt ends. ${ }^{[4]}$ Tulloch advises that one should consider the patient's age and maturity, the severity of the initial condition, growth pattern, and compliance before embarking on functional therapy. ${ }^{[5]}$

Since the discovery of the Herbst Appliance by Pancherz in the 1970s, many different non-compliant variants have come onto the market. They claim to allow greater freedom of movement of the mandible and allow lateral jaw movements to be carried out with ease. The major drawback with these appliances is the propensity with which fractures can occur, both in the appliance itself and in the support system. ${ }^{[6]}$

\section{FORSUS FATIGUE RESISTANT DEVICE (FFRD)}

The FFRD (3M Unitek, Monrovia) is an innovative threepiece telescoping spring for Class II correction. It comprises

\footnotetext{
Address for Correspondence:

Taher Manasawala, 7-, Bhumiraj Woods, Sector 4, Kharghar, Navi Mumbai - 410 210, Maharashtra, India.

Email: manasawalataher@gmail.com
}

Submission: 19 February 2021; Revision: 21 April 2021; Acceptance: 29 May 2021 
a $0.5 \times 3.0 \mathrm{~mm}$ spring bar (45\% nickel, $55 \%$ titanium) with a transparent plastic coating. ${ }^{[1]}$ The FFRD is an alternative interarch appliance for treating Class II malocclusion. ${ }^{[7,8]} \mathrm{A}$ mandibular push rod attaches directly to the lower archwire distal to the canines, and a telescoping spring attaches to the headgear tube with an L-pin or EZ module. The Forsus ${ }^{\mathrm{TM}}$ spring is supplied in four different lengths: $28 \mathrm{~mm}, 31 \mathrm{~mm}$, $34 \mathrm{~mm}$, and $37 \mathrm{~mm}$, in each case for right and left fitting. Measurements are made in habitual occlusion mesially from the headgear tube of the upper first molar distally to the bracket of the lower canine. $12 \mathrm{~mm}$ is added to this measurement (4 mm play, $4 \mathrm{~mm}$ headgear tube, $4 \mathrm{~mm}$ activation) and this gives the length of the module to be used. ${ }^{[1]}$ Forces are unloaded when the patient's jaw opens, resulting in intrusive rather than extrusive force vectors. In contrast, Class II elastics load upon jaw opening, producing extrusive forces at their terminal ends and potentially undesirable side effects as the occlusal plane are rotated clockwise. The FFRD exerts a continuous force with more elasticity and flexibility than the Herbst, permitting a greater range of mandibular opening and lateral movements during speech, chewing, and swallowing. ${ }^{[9]}$

The Forsus springs require anchorage preparation before they can be placed to minimize unwanted movement. It is necessary to align and level arches prior to insertion of the device with a minimum of $0.016 \times 0.022$-inch stainless steel
(SS) required in a 0.018 -inch slot or a $0.019 \times 0.025$-inch wire in a 0.022 -inch slot. The archwires should be tightly cinched and lower canines tied into the archwire with steel ligatures. The appliance places a distal force on the upper arch and a mesial force on the lower arch, allowing for Class II correction. Incremental forces can be created by placing 2-mm split crimps onto the pushrod, increasing the pressure on the spring. ${ }^{[6]}$

\section{CASE REPORT}

A 13-year-old female patient having a chief complaint of forwardly placed anterior teeth had reported with class II skeletal base having orthognathic maxilla and retrognathic mandible with a retruded chin. The patient exhibited horizontal growth pattern with competent lips, obtuse nasolabial angle, and a deep mentolabial sulcus [Figure 1]. The patient had a convex facial profile with an overjet of $7 \mathrm{~mm}$ showing dental class II molar and canine relationship bilaterally. There was mild proclination of upper and lower incisors with mild crowding in the maxillary anterior region. The upper midline was shifted on the right side by $3 \mathrm{~mm}$ [Figure 2].

The cephalometric analysis of the patient dictated class 2 skeletal base with $\mathrm{SNB}$ angle of $75^{\circ} \mathrm{ANB}$ of $7^{\circ}$ and BETA angle

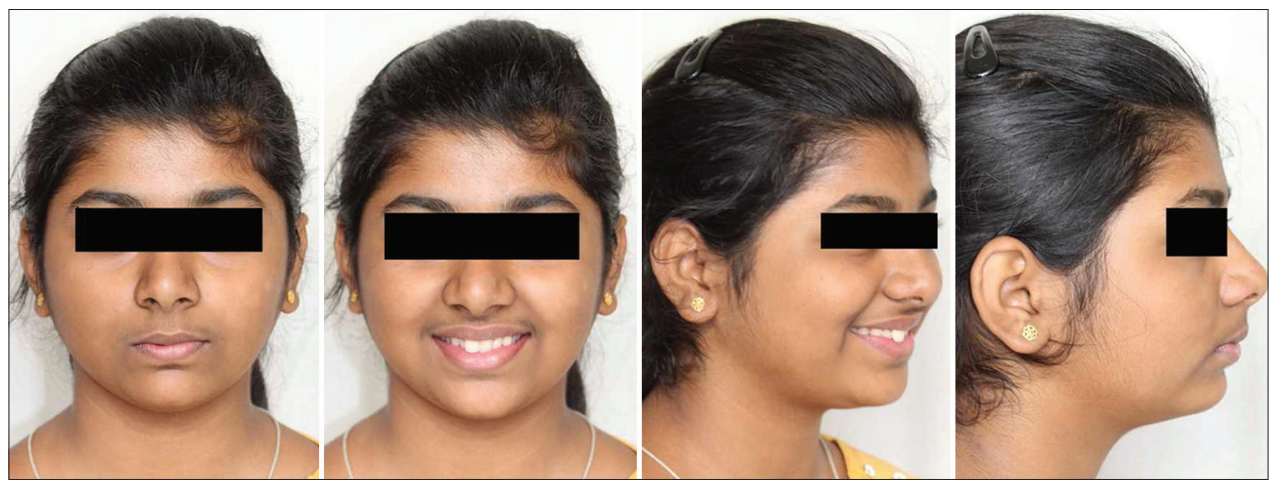

Figure 1: Pre-treatment extraoral photographs

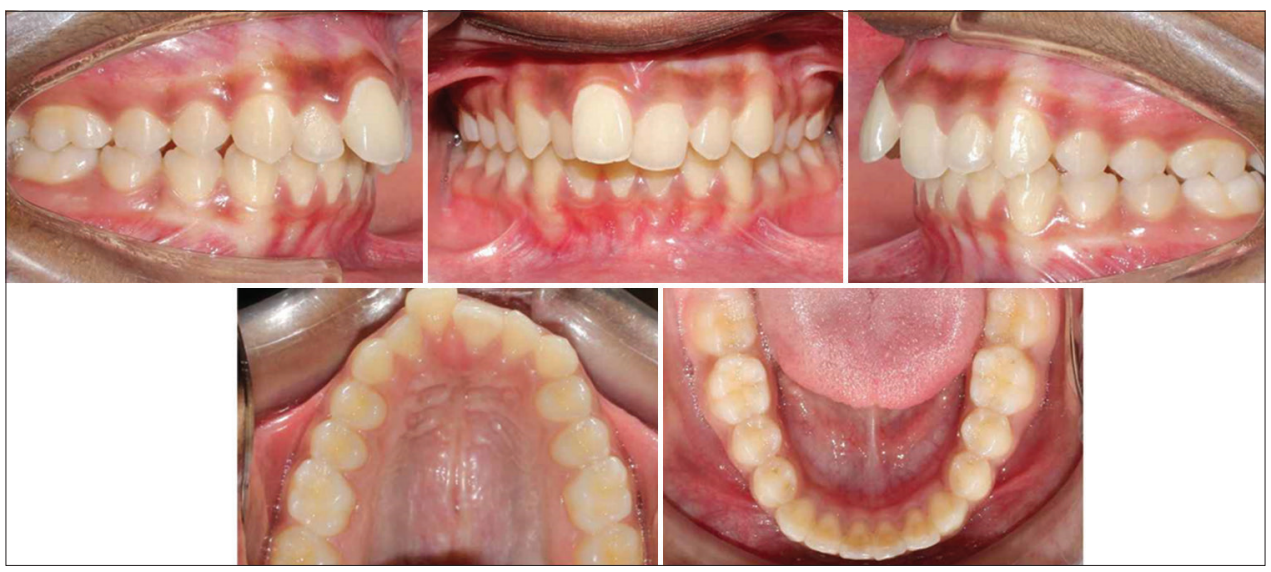

Figure 2: Pre-treatment intraoral photographs 
of 22. The upper incisors showed a value of $34 \% / 4 \mathrm{~mm}$ and lower incisors of $29 \% / 4 \mathrm{~mm}$ [Table 1]. The cervical vertebrae evaluation indicated the MATURATION STAGE (Hassal and Farman) $)^{[10]}$ as per which it could be predicted that the patient is towards the end of her pubertal growth spurt and the Visual treatment objective of the patient was positive as well [Figure 3].

After all the diagnostic evaluation it was decided to treat the patient with a non-extraction treatment therapy with a

Table 1: Pre and post functional cephalometric analysis

\begin{tabular}{lccc}
\hline Parameters & $\begin{array}{c}\text { Normal } \\
\text { value }\end{array}$ & Pretreatment & $\begin{array}{c}\text { Post } \\
\text { functional }\end{array}$ \\
\hline SNA & $82 \pm 2^{\circ}$ & $82^{\circ}$ & $80^{\circ}$ \\
SNB & $80 \pm 2^{\circ}$ & $75^{\circ}$ & $76^{\circ}$ \\
ANB & $2 \pm 4^{\circ}$ & $7^{\circ}$ & $4^{\circ}$ \\
WITS appraisal & $-1 \mathrm{~mm}$ & $3 \mathrm{~mm}$ & $2 \mathrm{~mm}$ \\
Effective Maxillary & $96 \pm 4 \mathrm{~mm}$ & $85 \mathrm{~mm}$ & $84 \mathrm{~mm}$ \\
Length & & & \\
Effective & $127 \pm 6 \mathrm{~mm}$ & $99 \mathrm{~mm}$ & $101 \mathrm{~mm}$ \\
Mandibular Length & & & \\
Angle of convexity & $-8.5 \pm 10^{\circ}$ & $12^{\circ}$ & $10^{\circ}$ \\
Beta Angle & $27-35^{\circ}$ & $22^{\circ}$ & $26^{\circ}$ \\
FMA & $22-25^{\circ}$ & $20^{\circ}$ & $27^{\circ}$ \\
Y axis & $53^{\circ}$ & $60^{\circ}$ & $70^{\circ}$ \\
LAFH & $67-69 \mathrm{~mm}$ & $50 \mathrm{~mm}$ & $54 \mathrm{~mm}$ \\
Sn-Go-Gn & $32^{\circ}$ & $27^{\circ}$ & $29^{\circ}$ \\
Upper Incisor to NA & $22^{\circ} / 4 \mathrm{~mm}$ & $34^{\circ} / 4 \mathrm{~mm}$ & $22^{\circ} / 4 \mathrm{~mm}$ \\
Upper Incisor to FH & $107^{\circ}$ & $115^{\circ}$ & $107^{\circ}$ \\
plane & & & \\
Lower Incisor to NB & $25^{\circ} / 4 \mathrm{~mm}$ & $29^{\circ} / 4 \mathrm{~mm}$ & $32^{\circ} / 6 \mathrm{~mm}$ \\
Lower Incisor to & $90^{\circ}$ & $105^{\circ}$ & $105^{\circ}$ \\
Mand Plane & & & \\
Interincisal angle & $135.4^{\circ}$ & $120^{\circ}$ & $120^{\circ}$ \\
Overjet & $2 \mathrm{~mm}$ & $7 \mathrm{~mm}$ & $2 \mathrm{~mm}$ \\
Overbite & $2 \mathrm{~mm}$ & $0 \mathrm{~mm}$ & $3 \mathrm{~mm}$ \\
Nasolabial angle & $102 \pm 8^{\circ}$ & $122^{\circ}$ & $120^{\circ}$ \\
Lip strain & $1 \mathrm{~mm}$ & $3 \mathrm{~mm}$ & $2 \mathrm{~mm}$ \\
Lower Lip to E line & $-2 \mathrm{~mm}$ & $-2 \mathrm{~mm}$ & $0 \mathrm{~mm}$ \\
Upper Lip to S line & $0 \mathrm{~mm}$ & $1 \mathrm{~mm}$ & $0 \mathrm{~mm}$ \\
\hline
\end{tabular}

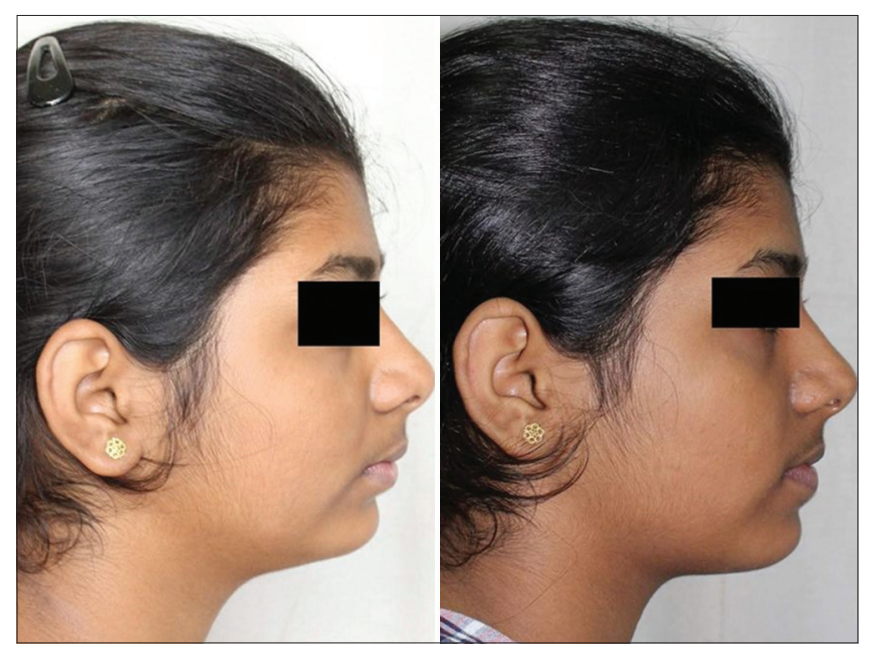

Figure 3: Clinical visualized treatment objective fixed functional appliance followed by finishing and settling. Leveling and aligning were initiated using $0.022 \mathrm{MBT}$ preadjusted edgewise bracket prescription using $0.016 \mathrm{NiTi}$ wires in both the arches. The $2^{\text {nd }}$ molars were banded as well and involved for anchorage preparation. Transpalatal arch in the maxillary and lingual arch in the mandibular arch was given respectively during the initial leveling and aligning.

After 6 months of treatment, adequate leveling and alignment had been achieved for placement of the FFRD. Upper and lower $0.019 " \times 0.025 " \mathrm{SS}$ wires were placed, and pigtail ligation was used in both arches from the first molar to the first molar. Both archwires were cinched back for reinforced anchorage. The mandible was advanced to a Class I molar relationship, and the FFRD was inserted bilaterally [Figure 4].

\section{RESULT}

Final arch coordination and detailing were completed, after 18 months of treatment [Figure 5]. Improved maxillomandibular relation was established by reduction in ANB angle and increase in Beta angle [Table 1]. Intraorally class I molar and canine relation was obtained bilaterally [Figure 5]. Patient's facial profile showed significant improvement [Figure 6].

\section{DISCUSSION}

Conversion of the class II division 2 into a division 1 is essential to free the restriction of the upper incisors on the lower incisors to allow maximal advancement of the mandible with the FFRD. Removable functional appliances are quite effective, but they rely heavily on patient cooperation for achieving predictable results in a reasonable time frame. Besides this, there are many difficulties faced during performing other functions like speech with these appliances. To eliminate these drawbacks, fixed bite jumping appliance have been developed. ${ }^{[1]}$

Jones $(2008)^{[8]}$ in a study stated that FFRD as compared to class II elastics leads to a significant mesial movement of the lower molar and total molar correction in the Forsus group. Furthermore, Franchi and Bacetti (2011) ${ }^{[11]}$ assessed the overall effects of FFRD in comparison with fixed orthodontic treatment in the correction of class II malocclusion. They concluded that FFRD showed significant changes in the maxillomandibular relations with restraining effect on the maxilla.

The wide variety of functional appliances that are available to posture the mandible forward for the correction or Class II skeletal discrepancies which, gives the orthodontist a wide variety of appliance selection and at the same time challenges the rationale for selecting the most appropriate appliance. 

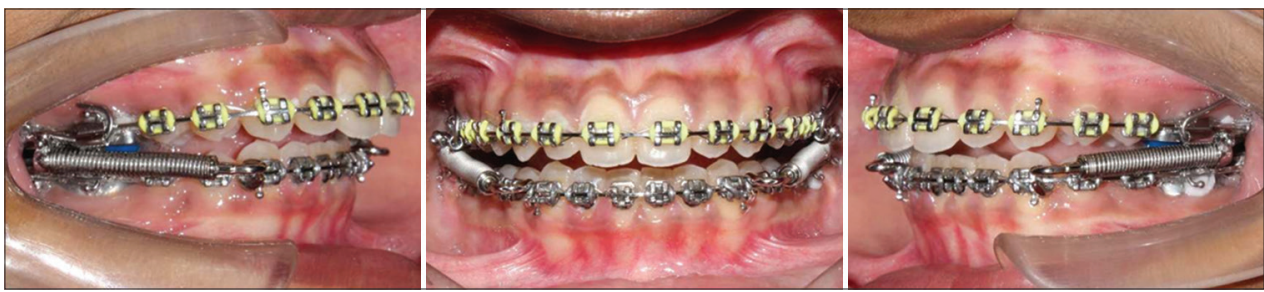

Figure 4: FORSUS appliance in place+
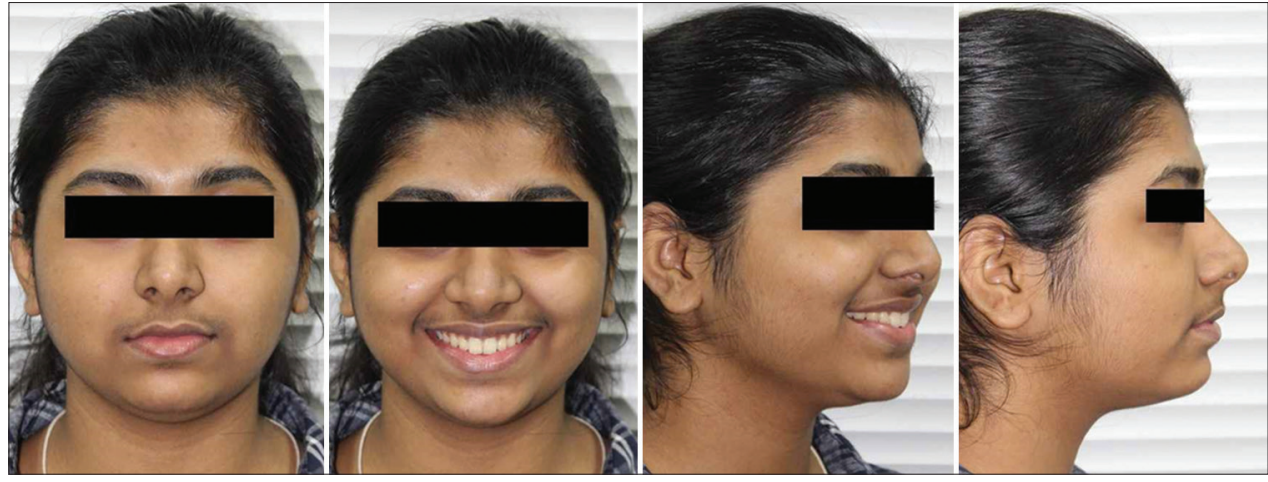

Figure 5: Post-treatment intraoral photographs
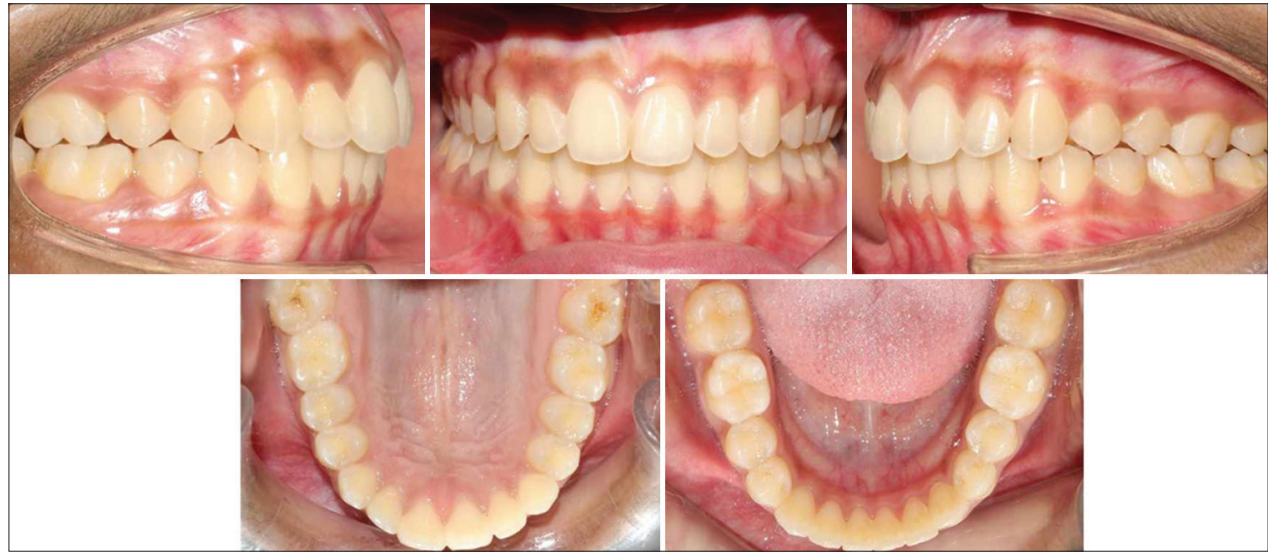

Figure 6: Post-treatment extraoral photographs

The decision as to which appliance is to be used is based primarily on the status of the dental and skeletal tissues of the patient, the type of dental response desired, the rate and amount of skeletal growth remaining, and the degree of co-operation anticipated from the patients. ${ }^{[1]}$

\section{CONCLUSION}

Newer innovations have come into this field, and with newer technology, it is up to the clinician to decide as to when, where, and how to apply it appropriately. As we all know, it is not the appliance and the philosophy, but the clinician behind the appliance who can make the difference between success and failure.

\section{REFERENCES}

1. Ahuja D, Holla AK, Parashar S. A brief review of forsus: Frd; hybrid fixed functional appliance. Asian J Dent Res 2016;1:327.

2. Arici S, Akan H, Yakubov K, Arici N. Effects of fixed functional appliance treatment on the temporomandibular joint. Am J Orthod Dentofac Orthop 2008;133:809-14.

3. Moyers RE. Handbook of Orthodontics. $4^{\text {th }}$ ed. Chicago: Yearbook Publishers; 1988.

4. McNamara JA, Brudon WL. Orthodontic and Orthopedic Treatment in the Mixed Dentition. Ann Arbor: Needham Press; 1992.

5. Tulloch JF, Proffit WR, Phillips C. Influences on the outcome of early treatment for class II malocclusion. Am J Orthod Dentofacial Orthop 1997;111:533-42.

6. Ross AP, Gaffey BJ, Quick AN. Breakages using a unilateral fixed functional appliance: A case report using the forsus TM fatigue resistant device. J Orthod 2007;34:2-5. 
7. Vogt W. The forsus fatigue resistant device. J Clin Orthod 2006;40:368-77.

8. Jones G. Buschang PH, Kim KB, Oliver DR. Class II non-extraction patients treated with the forsus fatigue resistant device versus intermaxillary elastics. Angle Orthod 2008;78:332-8.

9. Sood S. The forsus fatigue resistant device as a fixed functional appliance. J Clin Orthod 2011;45:463-6.

10. Hassel B, Farman AG. Skeletal maturation evaluation using cervical vertebrae. Am J Orthod Dentofac Orthop 1995;107:58-66.
11. Franchi L, Alvetro L, Giuntini V, Masucci C, Defraia E, Baccetti T. Effectiveness of comprehensive fixed appliance treatment used with the forsus fatigue resistant device in class II patients. Angle Orthod 2011;81:678-83.

How to cite this article: Manasawala T, Shetty V, Shenava, Batni S. Correction of Class II Malocclusion in a Patient Using the FORSUS Fatigue

Resistant Appliance -A Case Report. Int J Dent Med Spec 2021;8(1):15-19.

Source of Support: None; Conflicts of Interest: None 